\title{
Synchronous double cancers of primary hepatocellular carcinoma and cholangiolocellular carcinoma: a case report
}

\author{
Kazuhiro Suzumura ${ }^{1 *}$, Yasukane Asano ${ }^{1}$, Tadamichi Hirano ${ }^{1}$, Toshihiro Okada ${ }^{1}$, Naoki Uyama ${ }^{1}$, Nobuhiro Aizawa², \\ Hiroko lijima ${ }^{2}$, Keiji Nakasho ${ }^{3}$, Shuhei Nishiguchi ${ }^{2}$ and Jiro Fujimoto ${ }^{1}$
}

\begin{abstract}
Synchronous double cancers consisting of hepatocellular carcinoma (HCC) and cholangiolocellular carcinoma (CoCC) are extremely rare. We herein report a surgical case of synchronous double cancers in a patient with primary HCC and CoCC. A 45-year-old man with hepatitis B was admitted to our hospital with hepatic tumors. The level of protein induced by vitamin K antagonist (PIVKA-II) was found to be elevated. Computed tomography $(\mathrm{CT})$ revealed a 23- $\mathrm{mm}$ tumor with early-phase enhancement and late-phase washout in the 6th segment of the liver, and a 10-mm tumor with slight early-phase enhancement and late-phase washout in the 7th segment of the liver. Magnetic resonance imaging (MRI) revealed that the two tumors in the 6th and 7th segments showed low intensity on T1-weighted images and high intensity on T2-weighted images. Based on those preoperative examinations, the liver tumors were diagnosed as multiple primary hepatocellular carcinomas. The patient underwent a posterior segmentectomy. A histopathological examination revealed that the tumor of the 6th segment of the liver was moderately differentiated HCC, and that the tumor of the 7th segment of the liver was CoCC. The postoperative course was uneventful. However, lymph node recurrence was observed 6 months later and the patient died 20 months after surgery. There are only six reported surgical cases of synchronous double primary liver cancers consisting of HCC and CoCC. We are of the opinion that curative resection may be an effective treatment for double cancer consisting of HCC and CoCC, and that it may provide long-term survival.
\end{abstract}

Keywords: Cholangiolocellular carcinoma, Hepatocellular carcinoma, Double cancer, Hepatectomy, Recurrence

\section{Background}

The incidence of synchronous double cancers consisting of different primary hepatic tumors is very low. Most cases involve patients with double cancers consisting of hepatocellular carcinoma (HCC) and intrahepatic cholangiocellular carcinoma (CCC). Cholangiolocellular carcinoma $(\mathrm{CoCC})$ is a rare form of primary liver cancer that was first proposed by Steiner and Higginson in 1959 [1]. There are only five other reported cases of synchronous double primary liver cancers consisting of

\footnotetext{
* Correspondence: ssuzumu@hyo-med.ac.jp

${ }^{1}$ Department of Surgery, Hyogo College of Medicine, 1-1, Mukogawa,

Nishinomiya, Hyogo 663-8501, Japan

Full list of author information is available at the end of the article
}

HCC and CoCC [2-6]. We herein report a surgical case of synchronous double cancers in a patient with primary $\mathrm{HCC}$ and $\mathrm{CoCC}$ and review the literature.

\section{Case presentation}

A 45-year-old man with hepatitis B was admitted to our hospital because of hepatic tumors. He was administered a daily dose of $0.5 \mathrm{mg}$ entecavir. He had a history of treatment for esophageal varices. The results of a physical examination were normal. A laboratory examination produced the following results: white blood cell count, 3000/ $\mu$; red blood cell count, $473 \times$ $10^{4} / \mu \mathrm{l}$; hemoglobin, $13.1 \mathrm{~g} / \mathrm{dl}$; platelet count, $8.7 \times$ $10^{4} / \mu \mathrm{l}$; albumin, $4.5 \mathrm{~g} / \mathrm{dl}$; total bilirubin, $1.7 \mathrm{mg} / \mathrm{dl}$; and 
prothrombin time (percent), 79\%. The alanine aminotransferase, aspartate aminotransferase, alkaline phosphatase, lactate dehydrogenase, and $\gamma$-glutamyl transpeptidase levels were within the normal ranges. The indocyanine green retention value at 15 min was $34 \%$. The patient was hepatitis $\mathrm{B}$ virus-related antigen ( $\mathrm{HBsAg}$ )-positive and HBs antibody (HBsAb)- and hepatitis $C$ virus antibody (HCVAb)-negative. The serum HBV-DNA was not detected. The level of protein induced by vitamin $\mathrm{K}$ antagonist (PIVKA-II) was found to be elevated ( $317 \mathrm{mAU} / \mathrm{ml})$, but the level of alpha-fetoprotein (AFP) was within the normal limits.

Abdominal ultrasonography (US) showed a welldefined 23-mm hypoechoic mass that was heterogeneous

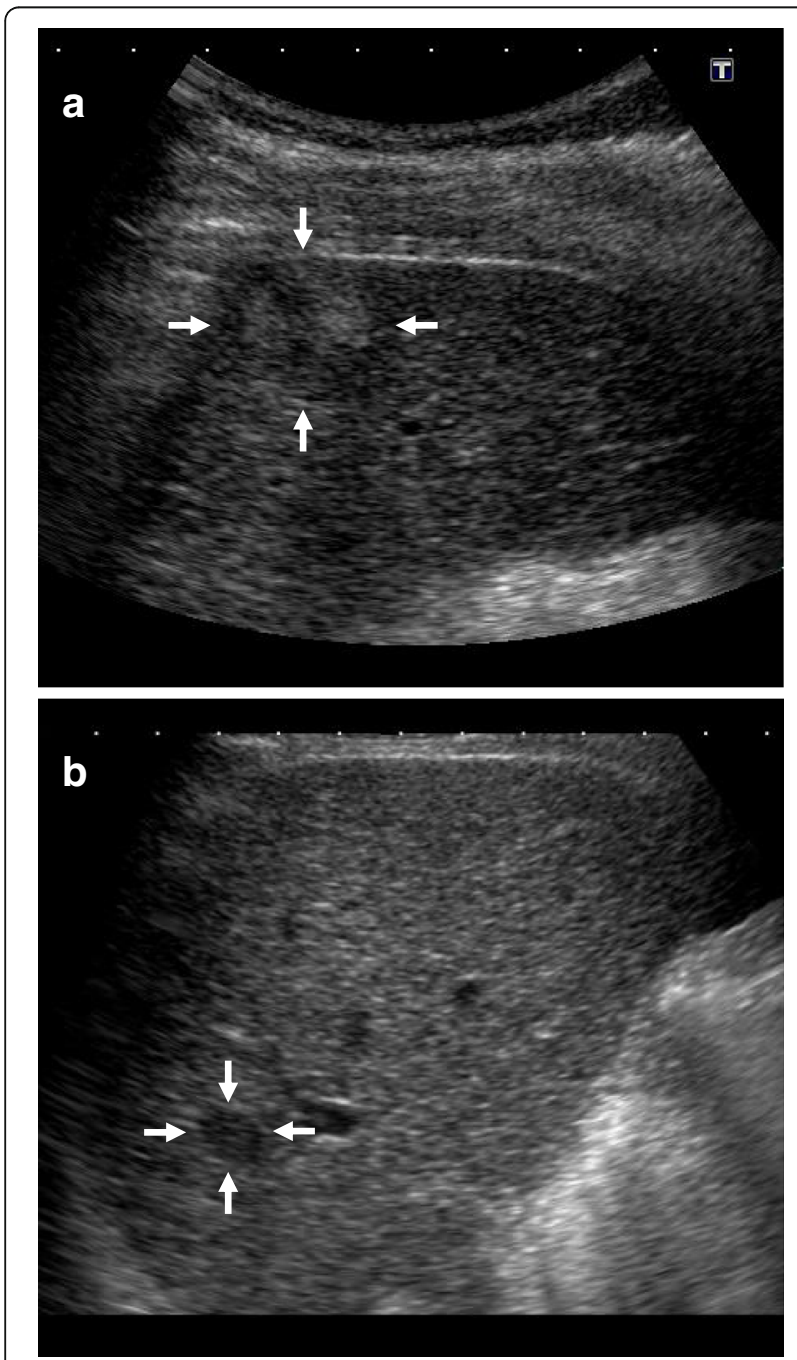

Fig. 1 Abdominal ultrasonography (US) showed the two tumors. a A well-defined 23-mm hypoechoic mass that was heterogeneous on the inside was observed in the $6^{\text {th }}$ segment of the liver (arrows). b A slightly ill-defined $10-\mathrm{mm}$ hypoechoic mass that was homogeneous on the inside was observed in the $7^{\text {th }}$ segment of the liver (arrows) on the inside in the 6th segment of the liver (Fig. 1a), and a slightly ill-defined 10 - $\mathrm{mm}$ hypoechoic mass that was homogeneous on the inside in the 7th segment of the liver (Fig. 1b). Abdominal computed tomography (CT) revealed a $23-\mathrm{mm}$ tumor with early phaseenhancement and late-phase washout in the 6th segment of the liver (Fig. 2a, b), and a 10-mm tumor with slight early-phase enhancement and late-phase washout in the 7th segment of the liver (Fig. 2c, d). Abdominal magnetic resonance imaging (MRI) revealed that the two tumors in the 6th (Fig. 3a, b) and 7th (Fig. 3c, d) segments showed low intensity on T1-weighted images and high intensity on T2-weighted images. Based on these preoperative examinations, the liver tumors were diagnosed as multiple primary hepatocellular carcinomas. The patient underwent a posterior segmentectomy. We did not perform lymph node dissection, because we diagnosed multiple primary hepatocellular carcinomas preoperatively. The resected specimen showed that the tumor of the 6th segment of the liver was a 23-mm well-defined yellowish-white soft elastic lesion (Fig. 4a), and that the tumor of the 7 th segment was a $10-\mathrm{mm}$ irregular yellowish-white slightly hard elastic lesion (Fig. 4b). A histopathological examination revealed that the tumor of the 6th segment of the liver was moderately differentiated hepatocellular carcinoma (Fig. 5a), while that of the 7th segment was cholangiolocellular carcinoma (Fig. 5b). The pathological findings of the non-cancerous tissue were liver cirrhosis. An immunohistochemical examination of the tumor cells in the 7th segment of the liver was positive
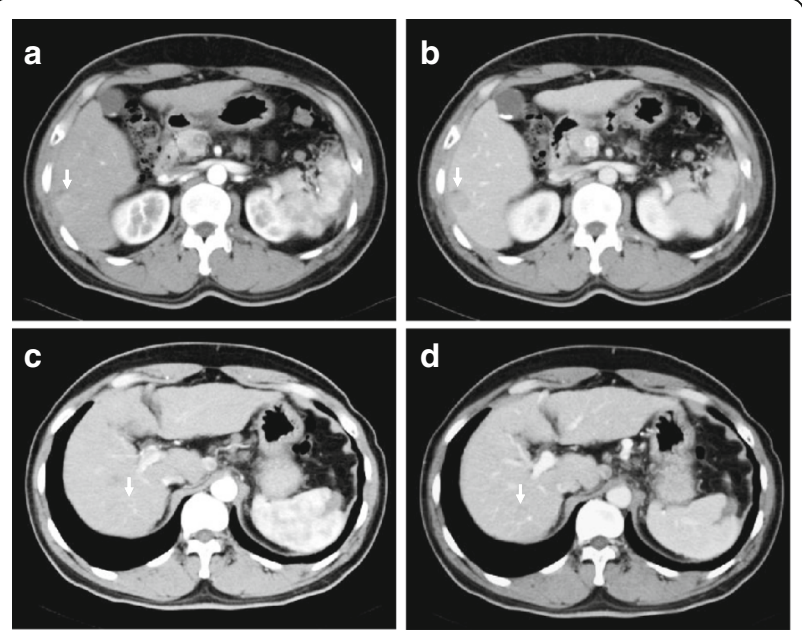

Fig. 2 Abdominal computed tomography (CT) of the two tumors. a $A$ 23-mm tumor had early-phase enhancement in the $6^{\text {th }}$ segment of the liver (arrow). b The tumor showed late-phase washout in the $6^{\text {th }}$ segment of the liver (arrow). c A 10-mm tumor showed slight early-phase enhancement in the $7^{\text {th }}$ segment of the liver (arrow). d The tumor showed late-phase washout in the $7^{\text {th }}$ segment of the liver (arrow) 


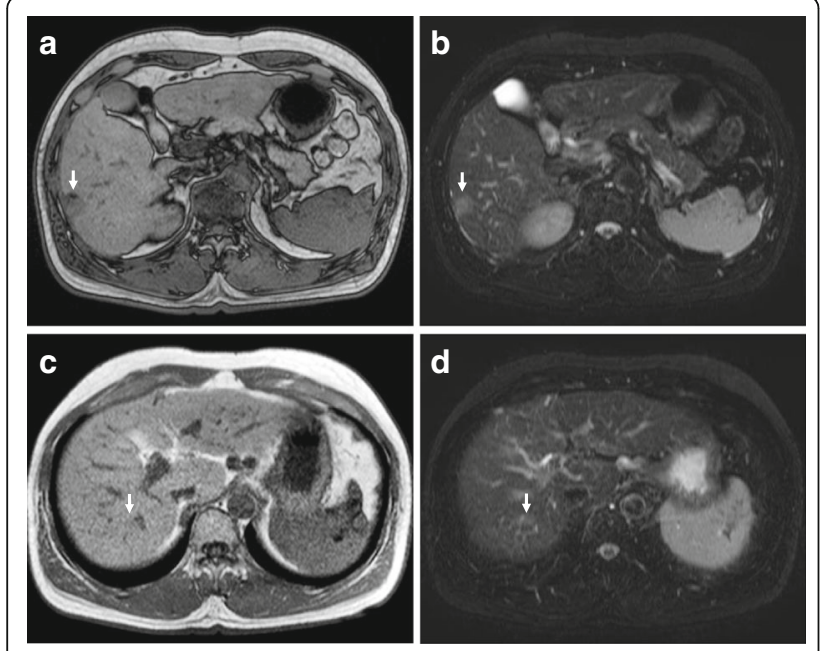

Fig. 3 Abdominal magnetic resonance imaging (MRI) of the two tumors. a The tumor in the $6^{\text {th }}$ segment of the liver showed low intensity on T1-weighted images (arrow). $\mathbf{b}$ The tumor in the $6^{\text {th }}$ segment of the liver showed high intensity on T2-weighted images (arrow). $\mathbf{c}$ The tumor in the $7^{\text {th }}$ segment of the liver showed low intensity on T1-weighted images (arrow). $\mathbf{d}$ The tumor in the $7^{\text {th }}$ segment of the liver showed high intensity on T2-weighted images (arrow)

for CK7, CK19, EMA, and MUC1/DF3 and was negative for EpCAM (Fig. 5c-g).

The postoperative course was uneventful and the patient was discharged on postoperative day 25 . However, 6 months later, lymph node recurrence of the hepatoduodenal ligament was observed. The patient died of multiple organ failure due to cancer recurrence 20 months after surgery.

\section{Discussion}

$\mathrm{HCC}$ and $\mathrm{CCC}$ are the two main primary liver cancers. CoCC is a rare form of primary liver cancer. In 1959, Steiner and Higginson described the distinct pathological characteristic of CoCC, which is derived from the cholangioles or canals of Hering [1]. The tumor was classified as a special type of CCC $[7,8]$. However, as a result of recent advances in the study and knowledge of hepatic progenitor or stem cells, CoCC is considered to originate from hepatic progenitor or stem cells [9-12].

The occurrence of synchronous double cancers consisting of different primary hepatic tumors is very low. Combined HCC and CCC is a rare primary liver tumor, and the reported incidence of combined HCC and CCC among pathologically diagnosed primary liver cancers was only $0.54 \%$ [13]. Allen and Lisa defined three types of HCC-CCC: (a) HCC and CCC are present at different sites within the same liver (double cancer type), (b) HCC and CCC are present at adjacent sites and mingle with each other but are
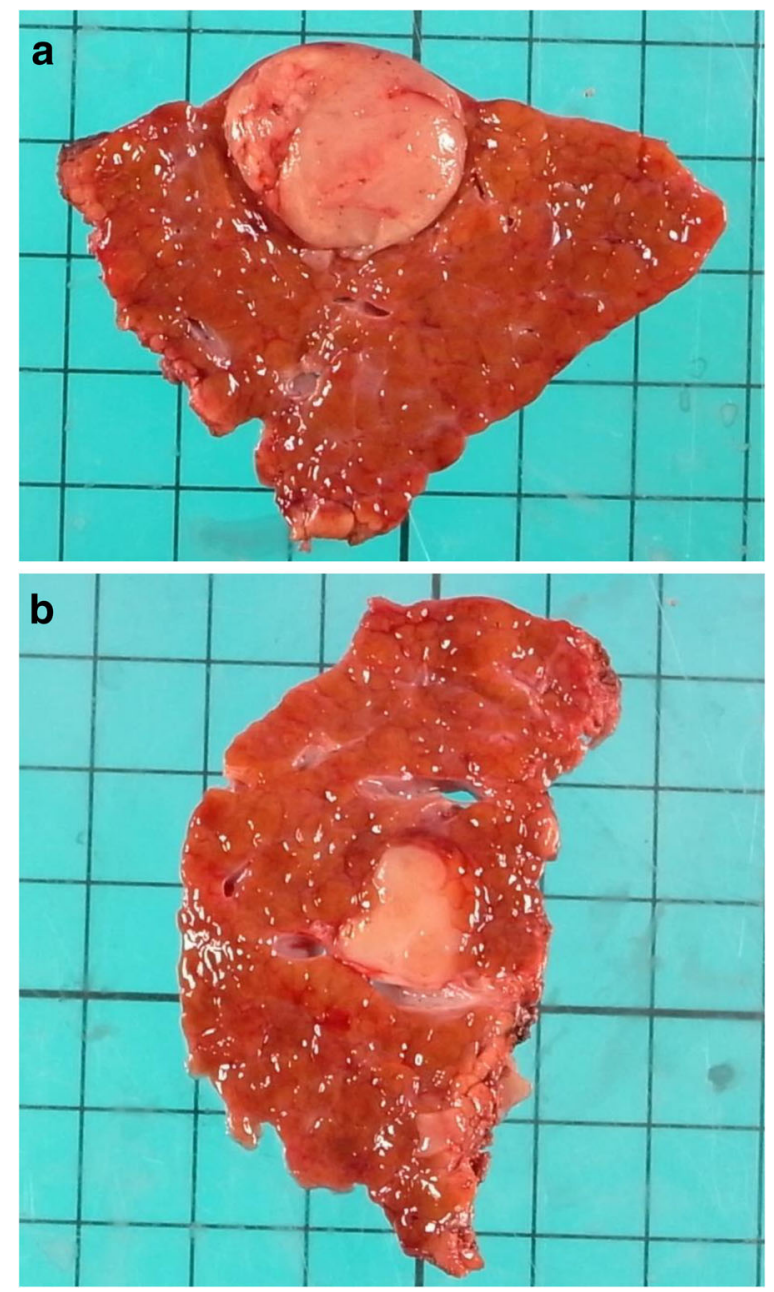

Fig. 4 The resected specimen showed two tumors. a The tumor of the $6^{\text {th }}$ segment of the liver was a 23-mm well-defined yellowish-white soft elastic lesion. $\mathbf{b}$ The tumor of the $7^{\text {th }}$ segment of the liver was a $10-\mathrm{mm}$ irregular yellowish-white slightly hard elastic lesion

still recognizable as distinct tumors (combined type), and (c) HCC and CCC components combined within the same tumor and indistinguishable as separate entities (mixed type) [14]. In the present case, we diagnosed a double cancer consisting of $\mathrm{HCC}$ and CoCC because the tumors were present at different sites within the same liver.

There are only six reports of double cancer consisting of $\mathrm{HCC}$ and $\mathrm{CoCC}$, including our case (Table 1) [2-6]. The patients in these cases were from 45 to 71 years of age (average 65 years); five of the patients were male and one was female. Two of the six patients were HCVAbpositive, two were HBsAg-positive, and two were HBsAb-positive. In all of the six cases, the AFP or PIVKA-II levels were found to be elevated, but the level of carcinoembryonic antigen (CEA) or carbohydrate antigen 19-9 (CA19-9) was not. The average sizes of the 

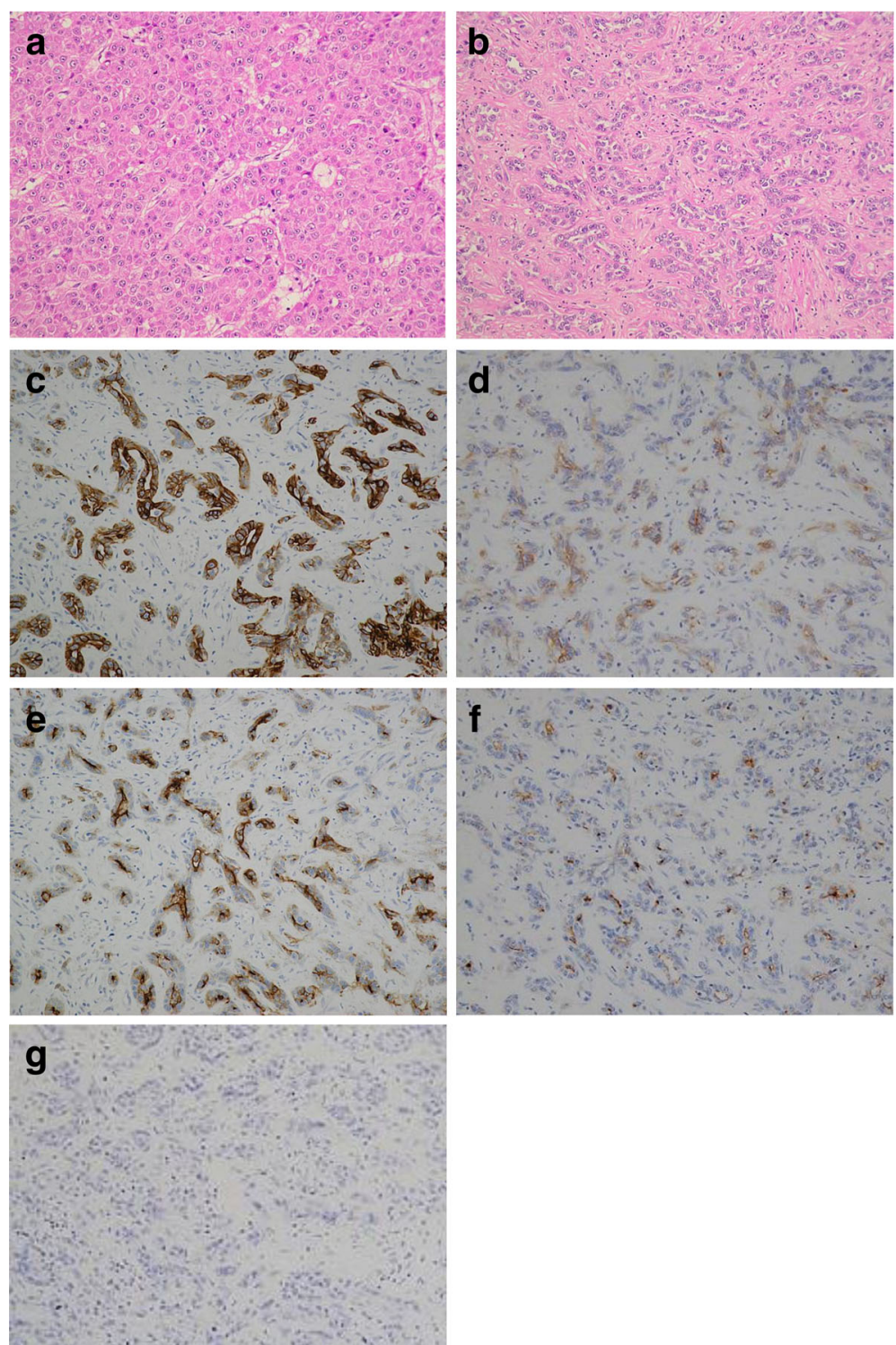

Fig. 5 The histopathological examination of the two tumors. a The tumor of the $6^{\text {th }}$ segment of the liver was moderately differentiated hepatocellular carcinoma (Hematoxylin and eosin staining, $\times 200$ ). $\mathbf{b}$ The tumor of the $7^{\text {th }}$ segment of the liver was cholangiolocellular carcinoma (Hematoxylin and eosin staining, $\times 200$ ). c The immunohistochemical examination of tumor cells from the $7^{\text {th }}$ segment of the liver revealed that they were CK7 positive $(\times 200)$. $\mathbf{d}$ The immunohistochemical examination of tumor cells from the $7^{\text {th }}$ segment of the liver revealed that they were CK19 positive ( $\times 200)$. e The immunohistochemical examination of tumor cells from the $7^{\text {th }}$ segment of the liver revealed that they were EMA positive $(\times 200)$. $\mathbf{f}$ The immunohistochemical examination of tumor cells from the $7^{\text {th }}$ segment of the liver revealed that they were MUC1/DF3 positive $(\times 200)$. $\mathbf{g}$ The immunohistochemical examination of tumor cells from the $7^{\text {th }}$ segment of the liver revealed that they were EpCAM negative $(\times 200)$

CoCC and HCC tumors (in greatest dimension) were $1.6 \mathrm{~cm}$ (range 0.8-2.2) and $2.8 \mathrm{~cm}$ (range 1.2-4.5), respectively. In the histopathological examinations of the non-cancerous portion of the liver, three patients had chronic hepatitis and two patients had liver cirrhosis.

The preoperative diagnosis of $\mathrm{CoCC}$ is extremely difficult using US, CT, and MRI. CoCC has been misdiagnosed as HCC, CCC, and metastatic liver cancer.
Recently, some reports have examined the imaging findings in cases of CoCC $[15,16]$. US shows a hypoechoic mass, CT shows uniform and complete enhancement or peripheral ring-like enhancement, and MRI shows isointensity or low intensity on T1-weighted images and high intensity on T2-weighted images. In our case, US showed a hypoechoic mass, CT showed slight earlyphase enhancement and late-phase washout, and MRI 
Table 1 The surgical cases of synchronous double cancers consisting of primary hepatocellular carcinoma and cholangiolocellular carcinoma

\begin{tabular}{|c|c|c|c|c|c|c|c|c|c|c|}
\hline Author & Year & Age & Sex & $\begin{array}{l}\mathrm{HBsAg} / \\
\mathrm{HBsAb} / \\
\mathrm{HCVAb}\end{array}$ & $\begin{array}{l}\text { AFP(ng/ml)/ } \\
\text { PIVKAll(mAU/ml) }\end{array}$ & $\begin{array}{l}\text { CEA(ng/ml)/ } \\
\text { CA19-9(U/ml) }\end{array}$ & $\begin{array}{l}\text { Cocc } \\
\text { location/ } \\
\text { size }\end{array}$ & $\begin{array}{l}\text { HCC } \\
\text { location/ } \\
\text { size }\end{array}$ & $\begin{array}{l}\text { Non- } \\
\text { cancerous } \\
\text { portion }\end{array}$ & Prognosis \\
\hline Matsuda [2] & 2006 & 70 & M & $(-) / N D /(+)$ & $N R / 2155$ & NR/NR & $\mathrm{S} 7 / 2.2 \mathrm{~cm}$ & $\mathrm{~S} 4 / 4 \mathrm{~cm}$ & $\begin{array}{l}\text { chronic } \\
\text { hepatitis }\end{array}$ & $\begin{array}{l}30 \text { months alive } \\
\text { without recurrence }\end{array}$ \\
\hline Ikeda [3] & 2010 & 64 & M & $(+) /(-) /(-)$ & $39.7 / 202$ & $\mathrm{ND} / \mathrm{ND}$ & $\mathrm{S} 8 / 2.2 \mathrm{~cm}$ & $\mathrm{~S} 8 / 1.7 \mathrm{~cm}$ & liver cirrhosis & $\begin{array}{l}8 \text { months alive } \\
\text { without recurrence }\end{array}$ \\
\hline Kawano [4] & 2012 & 68 & F & $(-) /(+) /(-)$ & $30.1 / 105$ & $2.9 / 25.1$ & $\mathrm{~S} 3 / 2 \mathrm{~cm}$ & $54 / 1.2 \mathrm{~cm}$ & ND & $\begin{array}{l}41 \text { months alive } \\
\text { without recurrence }\end{array}$ \\
\hline Sunahara [5] & 2013 & 71 & M & $(-) /(-) /(+)$ & $N R / 24458$ & $\mathrm{NR} / \mathrm{NR}$ & $\mathrm{S} 6 / 0.8 \mathrm{~cm}$ & $\mathrm{~S} 4 / 2.8 \mathrm{~cm}$ & $\begin{array}{l}\text { chronic } \\
\text { hepatitis }\end{array}$ & $\begin{array}{l}8 \text { months alive } \\
\text { without recurrence }\end{array}$ \\
\hline Takata [6] & 2014 & 71 & M & $(-) /(+) /(-)$ & $333.5 / 140$ & $0.6 / \mathrm{ND}$ & $\mathrm{S} 3 / 1.5 \mathrm{~cm}$ & $\mathrm{~S} 7 / 4.5 \mathrm{~cm}$ & $\begin{array}{l}\text { chronic } \\
\text { hepatitis }\end{array}$ & $\begin{array}{l}13 \text { months alive } \\
\text { without recurrence }\end{array}$ \\
\hline Our case & 2016 & 45 & $M$ & $(+) / N D /(-)$ & $2.7 / 317$ & $\mathrm{ND} / \mathrm{ND}$ & $\mathrm{S} 7 / 1 \mathrm{~cm}$ & $\mathrm{~S} 6 / 2.3 \mathrm{~cm}$ & liver cirrhosis & 20 months died \\
\hline
\end{tabular}

$N D$ not described, $N R$ normal range

showed low intensity on T1-weighted images and high intensity on T2-weighted images. However, we misdiagnosed CoCC as HCC.

A previous report indicated that the most frequent site of recurrence in surgically resected $\mathrm{CoCC}$ is the liver, and that no lymph node recurrence was seen [17]. Our case was the only case to show lymph node recurrence among the six reported cases of double cancer consisting of $\mathrm{HCC}$ and CoCC.

Ariizumi et al. [17] reported that the 5-year survival rate for patients who underwent curative surgery was significantly higher in the CoCC (75\%) than in the intrahepatic CCC (33\%). Among the six reported patients who underwent curative resection for double cancer consisting of $\mathrm{HCC}$ and $\mathrm{CoCC}$, five patients remained alive without recurrence at the time of the publication of the report; the only exception was our patient. Therefore, curative resection may be an effective treatment for double cancer consisting of $\mathrm{HCC}$ and $\mathrm{CoCC}$ and may provide long-term survival.

\section{Conclusions}

We reported a case of double primary $\mathrm{HCC}$ and $\mathrm{CoCC}$. Synchronous double cancers consisting of $\mathrm{HCC}$ and $\mathrm{CoCC}$ are extremely rare, with only six reported cases of resected double cancer consisting of $\mathrm{HCC}$ and $\mathrm{CoCC}$ in the literature, including our own. We are of the opinion that curative resection may be an effective treatment for double cancer consisting of HCC and CoCC, and that it may provide long-term survival.

\section{Acknowledgements}

This case report is not supported by any grants.

\section{Authors' contributions}

KS treated the patient, performed the acquisition and analysis of data, and wrote the manuscript. $\mathrm{YA}, \mathrm{TH}, \mathrm{TO}$, and $\mathrm{NU}$ treated the patient and performed the acquisition of data. NA, HI, and SN performed the preoperative examination and analysis of data. KN performed the histological examination and analysis of data. JF performed the operation, analysis of data, and total organization of writing the manuscript. All authors read and approved the final manuscript.

\section{Competing interests}

The authors declare that they have no competing interests.

\section{Consent for publication}

Written informed consent was obtained from the patient for publication of this case report and any accompanying images. A copy of the written consent is available for review by the Editor-in Chief of this journal.

\section{Author details}

'Department of Surgery, Hyogo College of Medicine, 1-1, Mukogawa, Nishinomiya, Hyogo 663-8501, Japan. ²Department of Internal Medicine, Hyogo College of Medicine, 1-1, Mukogawa, Nishinomiya, Hyogo 663-8501, Japan. ${ }^{3}$ Department of Pathology, Hyogo College of Medicine, 1-1,

Mukogawa, Nishinomiya, Hyogo 663-8501, Japan.

Received: 2 April 2016 Accepted: 10 November 2016

Published online: 22 November 2016

References

1. Steiner PE, Higginson J. Cholangiolocellular carcinoma of the liver. Cancer. 1959;12(4):753-9.

2. Matsuda M, Hara M, Suzuki T, Kono H, Fujii H. Synchronously resecyed double primary hepatic cancers-hepatocellular carcinoma and cholangiolocellular carcinoma. J Hepatobiliary Pancreat Surg. 2006;13(6): 571-6.

3. Ikeda M, Morise Z, Takeura C, Kagawa T, Tanahashi Y, Okabe Y, Tokoro T, Mizoguchi $Y$, Sugioka A. A resected case of double primary hepatic carcinomas-hepatocellular carcinoma and cholangiolocellular carcinoma. Jpn J Gastroenterol Surg. 2010:43(11):1141-5.

4. Kawano Y, Kikuchi S, Miyanishi K, Nagashima H, Hirakawa M, Tamura F, Yoshida M, Takahashi S, Takada K, Hayashi T, Sato T, Sato Y, Takimoto R, Kobune M, Kawamoto M, Mizuguchi T, Hirata K, Hasegawa T, Kato J. A case of double cholangiolocellular carcinoma and hepatocellular carcinoma complicated with non-alcoholic steatohepatitis. Kanzo. 2012;53(10):615-23.

5. Sunahara M, Kurauchi N, Tsunetoshi Y, Suzuki S, Kimura J, Kudo K, Shimoyama N. A case of synchronous double cancer of the liver consisting of cholangiolocellular and hepatocellular carcinomas in the background of chronic hepatitis C. J Jpn Soc Clin Surg. 2013;74(9):2572-6.

6. Takata H, Yoshida H, Mamada Y, Taniai N, Yoshioka M, Kawano Y, Mizuguchi Y, Shimizu T, Kakinuma D, Kanda T, Ueda J, Naito Z, Uchida E. A resected case of double cancer of hepatocellular carcinoma and intrahepatic 
cholangiocarcinoma with a component of cholangiolocellular carcinoma. Kanzo. 2014;55(2):106-14.

7. Nakanuma Y, Sripa B, Vatanasapt V. Intrahepatic cholangiocarcinoma. In: Hamilton SR, Aaltonen LA, editors. World Health Classification of Tumours. Pathology and Genetics of Tumours of the Digestive System. Lyon: IARC Press; 2000. p. 173-80.

8. Liver Cancer Study Group of Japan. General rules for the clinical and pathological study of primary liver cancer. 4th ed. Tokyo: Kanehara; 2000.

9. Shiota K, Taguchi J, Nakashima O, Nakashima M, Kojiro M. Clinicopathologic study on cholangiolocellular carcinoma. Oncol Rep. 2001;8(2):263-8.

10. Theise ND, Yao JL, Harada K, Hytiroglou P, Portmann B, Thung SN, Tsui W, Ohta H, Nakanuma Y. Hepatic "stem cell" malignancies in adults four cases. Histopathology. 2003;43(3):263-71.

11. Kozaka K, Sasaki M, Fujii T, Harada K, Zen Y, Sato Y, Sawada S, Minato H, Matsui O, Nakanuma Y. A subgroup of intrahepatic cholangiocarcinoma with an infiltrating replacement growth pattern and a resemblance to reactive proliferating bile ductules: "bile ductular carcinoma". Histopathology. 2007;51(3):390-400

12. Komuta M, Spee B, Borght S, Vos R, Verslype C, Aerts R, Yano H, Suzuki T, Matsuda M, Fujii H, Desmet VJ, Kojiro M, Roskams T. Clinicopathological study on cholangiolocellular carcinoma suggesting hepatic progenitor cell origin. Hepatology. 2008;47(5):1544-56.

13. Ikai I, Itai Y, Okita K, Omata M, Kojiro M, Kobayashi K, Nakanuma Y, Futagawa S, Makuuchi M, Yamaoka Y. Report of the 15th follow-up survey of primary liver cancer. Hepatol Res. 2004;28(1):21-9.

14. Allen RA, Lisa JR. Combined liver cell and bile duct carcinoma. Am J Pathol. 1949;25(4):647-55.

15. Fukukura Y, Hamanoue M, Fujiyoshi F, Sasaki M, Haruta K, Inoue H, Aiko T, Nakajo M. Cholangiolocellular carcinoma of the liver: $C T$ and MR findings. Comput Assist Tomogr. 2000;24(5):809-12.

16. Motosugi U, Ichikawa T, Nakajima H, Araki T, Matsuda M, Suzuki T, Fujii H, Nakazawa T, Yamaguchi H. Cholangiolocellular carcinoma of the liver: image findings. J Comput Assist Tomogr. 2009;33(5):682-8.

17. Ariizumi S, Kotera Y, Katagiri S, Nakano M, Nakanuma Y, Saito A, Yamamoto M. Long-term survival of patients with cholangiolocellular carcinoma after curative hepatectomy. Ann Surg Oncol. 2014;21:S451-8.

\section{Submit your manuscript to a SpringerOpen ${ }^{\circ}$ journal and benefit from:}

- Convenient online submission

- Rigorous peer review

- Immediate publication on acceptance

- Open access: articles freely available online

- High visibility within the field

- Retaining the copyright to your article 